\title{
Conceptual Exploration of the Rites of Passage With The Kumasi Central Market
}

\author{
Isaac Ossei Agyekumhene $^{1 *} \quad$ G. Y. Annum ${ }^{2} \quad$ Emmanuel Antwi ${ }^{2}$ \\ 1.Toase Senior High School, P. O. Box PC 28, Ashanti Region, Ghana \\ 2.Department of Painting and Sculpture, Faculty of Art, Kwame Nkrumah University of Science and Technology, \\ Ghana
}

\begin{abstract}
As a concept, the Rites of Passage - a phrase which was coined by the French anthropologist and folklorist Arnold van Gennep, is represented with paintings to depict the stages of life from the time of birth to death. This write-up, conceptually represents the behavioural tendencies at each stage of life with scenes captured from the Kumasi Central Market at the four major periods of the day which are morning, afternoon, evening and night. The captured scenes were selected based on the effect of light on the particular scene, specifically, the brightness of the hues, and its capability of portraying the specific period of the day. To achieve the exact optical effect, the selected scenes were photographically painted on canvasses. Descriptions were made of the scenes and were finally analysed. Thus Observatory, Participatory, Descriptive and Analytical methodologies were utilized to observe and capture snapshots of the scenes from the Kumasi Central Market, then painted the scenes, described them and finally analysed them respectively. The analyses resulted in conceptually portraying the Rites of Passage theory with the paintings. The statement or morals is that in nature, everything passes through the four stages of life and eventually dies. It is therefore concluded that nothing is permanent in life as it goes through several challenges and changes before finally deteriorating and dying or annihilating.
\end{abstract}

Keywords: Conceptual, Exploration, Rites of passage, Kumasi Central Market.

DOI: $10.7176 / \mathrm{JCSD} / 66-03$

Publication date:August $31^{\text {st }} 2021$

\section{Introduction}

he Central Market is a practical tool from which scenes could be philosophically analysed to link with the rites of passage. The Kumasi Central Market is bounded by the Railways, the Roman Hill, Akwatia Line, Asante New Town, Krobo Odumasi and Kejetia. It is within the proximity of the spectrum of the city's urbane mercantilism which are Adum and Kejetia. This article makes use of four scenes from the Kumasi central market for each of the four major periods of the day to symbolise the Rites of Passage in the life of man (Gennep, 1960). From the Kumasi central Market, four scenes were captured at four different periods of the day which are 1. Early Morning, 2. The afternoon, 3. Evening and 4. Night. The scenes were later painted on stretched canvases with colour, specifically, acrylics paint. As said above, the four scenes were purposefully studied and captured at the four major periods of the day to represent the rites of passage in nature which are Childhood, Youthful stage, Adult stage and Death respectively. This shows that each individual is liable to constant visible changes. The first of the four paintings which is a morning scene is titled Infantilism / Uncertainty. The afternoon scene is titled Vitality, whilst the scene captured in the evening is titled Preparation. The last one which is a night scene and symbolises the last stage in the life of man is also titled Death or Tranquillity.

\section{Methodology}

The primary data was collected from the Kumasi Central Market (the target population also abbreviated as $(\mathrm{KCM})$ and its auxiliaries which are the Kumasi Metropolitan Assembly (KMA) and the Fire Service at KMA and the Regional Fire Office at Chirapatre. The two main tools employed to gather data were questionnaire and interviews. Before that, the Central Market was visited on three occasions as preliminary survey to strategize how the interview process could be effectively conducted. This took place on three consecutive days from $4^{\text {th }}$ through $6^{\text {th }}$ December, 2010.

Two different groups of methodologies were utilized for this research which are briefly described here but with the details at the appropriate time of execution. (a) Field work Research Methods and (b) Studio Work Research Methods. For brevity and simplicity, I have cocooned the two different methods employed to acquire the secondary data on related materials and the primary data from the market under one umbrella as Field Work. The secondary data was accessed through the use of the Main Library, The College of Art and Social Sciences Library, both at KNUST. The British Council Library was also visited on one occasion and on two occasions the Ashanti Library was also visited. The purpose of visiting the said libraries was to gather secondary information from published materials like books, journals and periodicals. The internet was also very helpful and provided a fraction of the secondary data as we sat comfortably in a settee with our laptops. As no artist or a good researcher would end his/her research with the said facilities without being dubbed "an arm-chair researcher," 
we had to move out to conduct what could be called the actual field work research for the primary data. Two different modus operandi were adopted for the primary data collection. The first was to embark on observational trips to study the behavioural tendencies of colour at the said four different periods of the day at the Kumasi Central Market. The study was conducted in accordance with the variations of the weather condition. It was done to find the strength and effect of light on the market at the different times of the day. As earlier said, photographs of the scenes composed with humans and objects at the market were taken in the morning, afternoon, the evening and at night. The snapshots were taken of observed scenes which had the potential of eliciting conceptual interpretations. These observational study trips also served as an opportunity to purchase all the tools and materials that would be needed for the studio practice.

The next methodology was the conduct of interviews on three categories of respondents which were;

(1) The managers of the Kumasi Central Market at the Kumasi Metropolitan assembly

(2) The traders at the Central Market (people who actually sell at the market, particularly, those owning stores, stalls, tables, floor spaces) and finally;

(3) Ghanaian artists who explore colour or paint market scenes.

The interviews of the said three classes of respondents were conducted with interview guides, but with the third category who are the artists, the unstructured type of interview was mostly used. Pictures were taken of some of their works which we felt had bearings on our research.

(4) Data collected from the said sources were finally analysed.

The interview on the Kumasi Central Market was conducted with the view of ascertaining the phenomenological signification of the market to the users, particularly, the registered beneficiaries of the facilities and the authorities that manage the market. The interview took the form of structured type. The interview was conducted with questionnaires. Two hundred and fifty questionnaires were administered. It was an open-end questionnaire but due to the nature of business at the market, the answers provided by the respondents had to be personally filled. Out of the two hundred and fifty questionnaires administered, about one hundred and seventy, approximately seventy per cent $(70 \%)$ proved positive to our envisaged expectations. As no questionnaire was left with anyone, there were no 'casualties.'

The quantitative methodology was employed to ascertain the number of respondents and responses to certain particular questions that served the purpose of the research. That pertaining to the users was to find out the kind of items each respondent sold. This was to, particularly, ascertain the type of colours that could be emitted by the wares. Also, how important was the market to them. As some of them were hawkers, there were definitely some of the traders that depended more on the market than others. Though most of the respondents were literates we did not bother them with perception of hues or brightness of colour. Nevertheless a few of them could detect that the brightness of the colours of their wares could be intense at sunny mid-days and reduced in the evenings. This indicated that at least some of the traders at the market, in spite of their "untrained" nature had artistic eyes. It was found out that most of them have been in the market for a long period of time, some of them from as far back as thirty-five years ago, while a few joined the market not so long ago. This indicates that the market has for a long period helped in solving the employment canker of the country, those people who might be stranded in life may look on the market with religious reverence.

The interview as well aimed at finding out how comfortable were the users of the market. As to whether there were places of convenience, the answers were "Yes" and "No." There were three toilet facilities which were not equally distributed. There was one toilet facility on the top-floor of the story building which housed the Market Administrator and the Dressmakers. There was one private toilet which had been commercialized in one of the story-buildings bordering the market and along the main street towards the junction to the Roman Hill. The other was a public one at the Roman Hill.

Therefore, those who were positioned near to any of these found it convenient to give "Yes" as answer. Those whose positions were far away and, finding it difficult to walk such a distance to attend to nature's call, gave "No" as answers. Apart from the physical stress and time, one disadvantage was having to leave the wares in the care of a child or another person who may be tempted to take advantage of the long absence of the owner. The absence of the places of convenience attested to the fact that there is nothing without demerits. Nothing in this world is perfect. Not even humans who are created in the image of God. The secondary data was accessed through the use of archives, libraries and the internet as well as published and unpublished literature. As empirical studies, the works of selected artists who work in the same direction as our research were reviewed. Some of such artists were interviewed as well.

\subsection{Experimental Studies}

On the studio practice, we made use of Experimentative, Participatory and Observatory methods to construct canvases, primed and made experimental paintings with brush and painting knife. With painting knife and brushes, we experimented with the techniques of free strokes and impasto and finally settled on using only the brush. We then executed vivid replica or photographic images from the scenes captured from the Central Market. 
Analytical methodology was used to assess and conceptualize with the works while interpretative methodology was used to interpret or bring about the meanings and the morals derived.

\subsection{The Practical Projects}

Multiplicity of methodologies were utilized to accomplish the practical aspect or the studio work review of the research. Experimentative, Participatory and Analytical Methods were what were employed for the studio work. With the participatory methodology, canvases were stretched to form surfaces or spaces for the paintings. The canvases were later primed. After the primer was well dried, the works were sketched on the surfaces. With the utilization of Experimentative methodology, we executed one or two experimental paintings to ascertain whether the use of painting knife was better than the brush as well as the condition of fluidity, lustre and absorbency of the paints. We finally settled with the use of brush and completed all the four paintings. By employing analytical methodology, we philosophically linked them to the rites of passage as a concept.

\section{Results and Discussion}

The interviews conducted were very successful as the required data was accessed from the right respondents and that the analysis could effectively be established on sound premises. It established the premises or claim that the market was very conducive in terms of significance or importance to the users, the managers and the nation as a whole. As a concept, the scenes from the Kumasi Central Market, as a result, warranted the position of being used as a practical tool for conceptual analyses to symbolise the Rites of Passage. A mental demarcation of the market was made into ten segments from which respondents were randomly picked, based on selected groups, to facilitate the interview process. We wanted to verify the strength or heat from sunlight at the market from the morning, the afternoon to the evening. It was obvious that at night there wouldn't be any sunlight. Similarly, the research was conducted to also ascertain the strength of business in the morning, to be compared with that of the afternoon and the evening. At night, of course, was no trading activity as the market was then deserted and closed. The strength of the light and the brightness of the hues of colour as well as business in the morning, escalate by noon, and decline or wane in the evening to night. The said effects at the four periods of the day were researched to symbolize the four stages in the life of man popularly referred to as the Rites of Passage.

\subsection{The Rites of Passage}

The Concise Oxford Dictionary-Tenth Edition defines Rites as 1. "A religious or other solemn ceremony or act. 2. A body of customary observances characteristics of a church or a part of it. Rites of Passage, according to the Concise Oxford Dictionary, is derived from a Latin word which is ritus '(religious) usage.' It further goes on to define it as "A ceremony or event, e.g. marriage, marking an important stage in someone's life." According to The Concise Oxford Dictionary-Tenth Edition, Ritual or rite is any customary observance or practice. The Rites of Passage is defined by the same source as "A ritual performed in some cultures at times when an individual changes status (as from adolescence to manhood)." The rites of passage are the elaborate rites used in marking the various stages of life, from birth to death (Adom, Jephtar \& Kquofi, 2021). The Kumasi Central Market has been studied by many researchers which include artists who usually combine text and pictorial documentation in the form of Painting, Sculpture, communication Design, Ceramics, Metalwork, Photography etc, to make a meaningful research findings and discussions. The artistic modes of Photography and Painting were both employed in the research. Skills in photography was employed in the study and capturing of the right scene at the right spot, and at the right period of the day, to get the four major periods of the day. The artistic skills in Painting was employed to graphically paint the scenes to be analysed for the symbolism of the rites of Passage.

On one of our research trips we discovered that there were no drainage systems. We wondered whether they were underneath. The security and comfort of the users therefore dawned on us to restructure our prepared questionnaire for the Kumasi Metropolitan Assembly which, on the field survey, we discovered as the managers of the Kumasi Central Market earmarked which is the research population. We subsequently had to proceed to the Kumasi Metropolitan Assembly otherwise known as KMA where certain vital information about the market could be accessed. All such information could be linked to all the years in the life of man. The strength grows from morning signifying birth and childhood to its peak at the noon signifying youthful stage and decreases gradually throughout the evening which represents the adult stage and finally to death represented as night and eventuality. Throughout all the years of man from birth to death are challenges symbolized with the poor drainage systems and periodic fire outbreaks. We wanted to know from the KMA everything possible about the market which could make a meaningful impact on our objective of surveying the market which basically were to study the interplay of colour from objects and humans and also to assess the phenomenological signification of the market to the users, the managers and the community or the nation as a whole.

Like the importance of the market to the users, life or energy is so vital to man, symbolized with the significance of light to colour. Without light there would be no colour, without energy, there would be no life in man, similarly, it could be assumed that there would be no livelihood to the users if there were nothing like the 
Kumasi central Market from where they acquired their daily livelihood. As severally said, the paintings were analysed, as a concept to symbolize the passage of time and the rites performed at each stage in the life of man till death. In- between the four major periods are years when many incidences occur in the life of each man. Few of the incidences are happiness, but the major ones are challenges and hardships. We remember two maxims which are "Life is war," and "Man is born free but wherever he goes, he is in chains." We therefore had to symbolize the concept of hardships and challenges in the research at the Central Market to that of the activities in the life of man besides the concept of Rites of Passage.

The scenes used to symbolize the rites of passage was as a result of the different effects of light on them. With the effect of light on colour, the four major periods of the day could be clearly observed from the paintings. The significance of light to colour is such that it warrants a bit of elaboration on light, the source of colour, and what it actually is. Because colour is derived from light, (Guerlac 1986. p.3), it does not augur well to discuss colour without first dilating on its source which is light.

\subsection{Light}

The manner in which light contributes to the existence of colour has been variously discussed by many researchers but, from different angles, with slight omissions or additions to make theirs unique. Light is a form of energy that travels in a straight line and at three hundred million $(300,000,000)$ metres per second. Until something blocks its way, it will continue to travel at that rate, (Mwangi Saka \& Williams, 1974, pp. 5-8). Part or all the light may be reflected, absorbed or transmitted by the thing or object that obstructs the movement of the light when such an action takes place. Natural light (light from the sun, the moon and the stars) is white and is composed of seven colours of the rainbow (Mwangi, Saka\& Williams, 1974, p.12). The fact that light is described as white does not necessarily imply opaque white but rather a transparent state of white. I would prefer to term light colourless since all colours are seen through it in their purest states. Light is therefore transparent and could be termed as colourless.

As mentioned earlier, the sources of natural light are three, the sun, is what is basically utilised for this research as the hues of colour could not be well observed in the presence of moonlight or light from the stars. Aristotle asserts that light is not a material entity but the activity of a fire-like substance, which is similar to the ether that pervades the outermost sphere of the heavens, (Guerlac, 1986. p.6). The capacity to overcome a vast distance could not be said of the hues of colour. Depending on the size of an object and the distance from which it is observed, its hues may lose their quality or may not even be seen at all. This makes colour a bit subtle or delicate. a bit of review is thus to be made on colour to demystify it.

\subsection{Review on Colour}

Colour is said to emerge from natural light which is white (whether from the sun, the moon or the stars) and is composed of seven colours of the rainbow (Mwangi, Saka \& Williams, 1974, p.12). Colour has variously been defined by people like Isaac Newton, Plato, Aristotle, Kurt Nassau, to name but a few. It therefore has no definite definition but it suffices to know what has been said by others. As defined by Guerlac "Colour is derived from light." (Guerlac, 1986. p. 3). Culled from the World Book Encyclopaedia, the definition claims that, "Colour is what the eye sees when light strikes it. Everything in the world has colour; example green light is reflected to our eyes when we see grass". Plato defined colour as a particulate flame given off from every sort of the body. The colour particles differ in size. Plato asserts that if the colour particles which are different in size are equal to the component of the visual influence, they are imperceptible and the colour is called the "transparent" or the "diaphanous." Aristotle sooner adopted this term which also claimed that large particles from these bodies contract the compound, yielding the sensation of black, while similar particles dilate it, producing white. (Tanaka, Weiskopf \& Pepper, 2001. p. 211). Colour, as defined by Aristotle, is "The limit of the transparent medium in a definitely bounded body." But since then various definitions have also emerged. (Guerlac 1986, p. 6).

Nassau asserts that purity in colour is the amount of white light mixed with a hue. It could also be termed as saturation. The colours, red, yellow, and blue, known as primary colours can be combined in varying proportions to produce all other colours. Primary colours combined in equal proportions produce secondary colours. Two colours that combine to form white light are said to be complementary (Guerlac, 1986, p. 6). Lightness, continues Nassau, refers to the intensity or degree of shading; it corresponds to the subjective sensation of brightness. Purity is the amount of white light mixed with a hue. It could also be termed as saturation. As summation to a conglomerate of ideas including those stated above, I would simply define colour as "The body or physical appearance of any object that can be said as having hue, lightness or intensity." It will suffice, after the above definitions, to briefly elaborate on what actually is colour. 
analytical conceptualisation, hence its adoption as the theoretical foundation of the framework of this studiobased research. The resultant paintings of scenes from the market, therefore, generate analyses and conceptualizations from colour. An art work may be consisted of several elements yet a group of thought has it that art comprises five major elements which are: line, texture, colour, value and shape (Otto et al., 2002, p. 22). The shape of the form is magnified by colour which covers all the surface of the shape. Lines are magnified by colour; for without colour, lines could not be made nor seen properly. Without even a feel by touching, the texture of a surface could be felt or observed due to the action of colour depicting indentations and projections. Therefore, colour plays the most important role in an art work as it is the most globally appreciated element of art which appeals both to children and adults. It is observed that these elements of design especially colour, dims with diminishing of light and magnifies with the intensity of light (Guerlac, 1986, p.8.). While colour (which emerges from light), is the actual identity of the object, it could not be detected unless reflected in a kind of hue. Yet the shape of the art form defined by lines could be observed without much light. In most cases, even in pitch darkness, the texture of the surface could be felt with the hand for its effect. Yet without colour, as stated above, the object has no identity. Colour has received much attention from various artists both locally and internationally owing to its immense significance. Some of these artists utilise colour for aesthetic effects, psychological effects or purposes as well as colour symbolism and philosophical interpretations.

What beats our imagination is what causes colour to behave so differently in relation to the intensity of light? Is there any special quality in colour which enables it to behave the way it is? What influences colour to be able to behave in like manner? How does it relate to light? Why does it behave so differently in relation to proximity or distance from light? Having thrown a bit of light on light as the source of colour, and furthermore, its effect on colour, and finally what colour itself is, it is now ripe to discuss and analyse the paintings which resulted from colour to symbolically present the Rites of Passage in the life of man.

\subsection{Morning: Infantilism/Uncertainty}

This painting labelled as Figure 1, depicts the Central Lane of the Kumasi Central Market. Most of the traders are bringing their goods to the market while others are setting up for the day's business, so early in the morning. The hazy atmospheric condition is symbolic of the early stage as a child. Nothing is clearly seen or understood by the child as depicted by the painting. The picture depicts a wider bird-eye view of the market. It could be seen that the weather is cool and even foggy. When one draws nearer to an object, he/she clearly sees it through the fog but the farther the fog extends, the more difficult it becomes to see other objects through it. The colours of objects could be clearer identified only when close by. The mist is here used to represent the perception of the child, hardly does the child understand what are happening around. The closer one is confronted with a problem, the more clearly the problem is observed and the better it could be surmounted than that which is anticipated. The more the child advances in age, the more clearly are activities around are understood. like the dullness of the colours in the early stage of the day, so is the mental capacity of the child at the early stage in life. as the ours extend towards noon, more light is shed on the objects and their colours are seen as brighter than that of the morning. So, is it in the life of the child, as he/she grows, the more are the activities of people around, words and actions understood? 


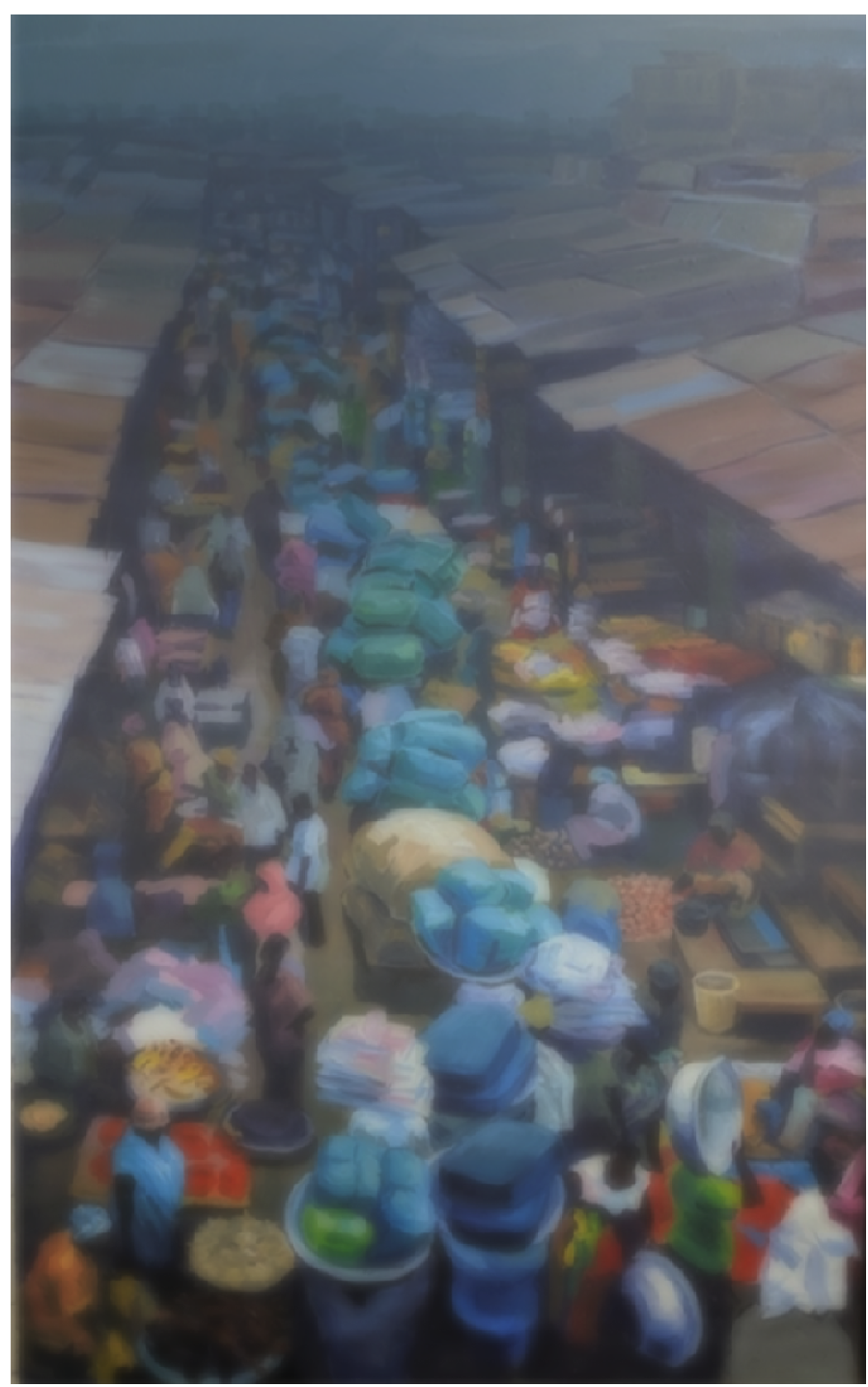

Figure 1. Morning Scene: Infantilism

Source: Photographed by the researchers

\subsection{Afternoon: Youthfulness and Vitality}

At this period, the vibrant colours and the sun's heat that can be intensely felt, is equated with youthfulness and the prime of energy. The picture, displayed as Figure 2, is a bird-eye view of the Kumasi Central market. As a bird-eye view it is obvious that the roof tops of the market would be the predominant objects in the picture. As observed in the picture, the roof tops do not transmit variety of colours and as such different hues. But the picture exudes energy and vitality which is symbolic of youthfulness. The market is an arena saturated with colour and as such myriads of hues. Yet standing at the spot where this scene was captured, virtually all the colourful hues are shelved under the roofs. Depending on where one is standing the brightness of the colours of the market would be differently observed. So is it in society, there are so many issues affecting society some of which are favourable and unfavourable. What are perceived to be good or favourable are seen differently by society depending on one's background or where one is coming from or 'standing.' For example, on the political divide, members of one group or party may observe an issue differently from members of another party.

The bottom line is that the farther one is from an object or where one is 'standing,' the ability to see well may be different or specifically worse than those nearer. The Akans have a proverb, "se wo ben asu kesez ho a na wohunu se ksto bon mu wa", which is transliterated as 'The nearer you are to an object the clearer you can see it. Literary, the nearer you are to the bank of a river, the likely you are to see how deep the crab can dig. At this period of the day, the sun is at its zenith and gives of its best as could be seen from the extent of brightness in the picture. At this time colour is so vitalized that it produces the highest level of hues. Such vitality in colour is equated with vitality in live. The picture is thus employed as a medium to depict energy and vitality at the youthful stages where man is able to make the best use of his life. 


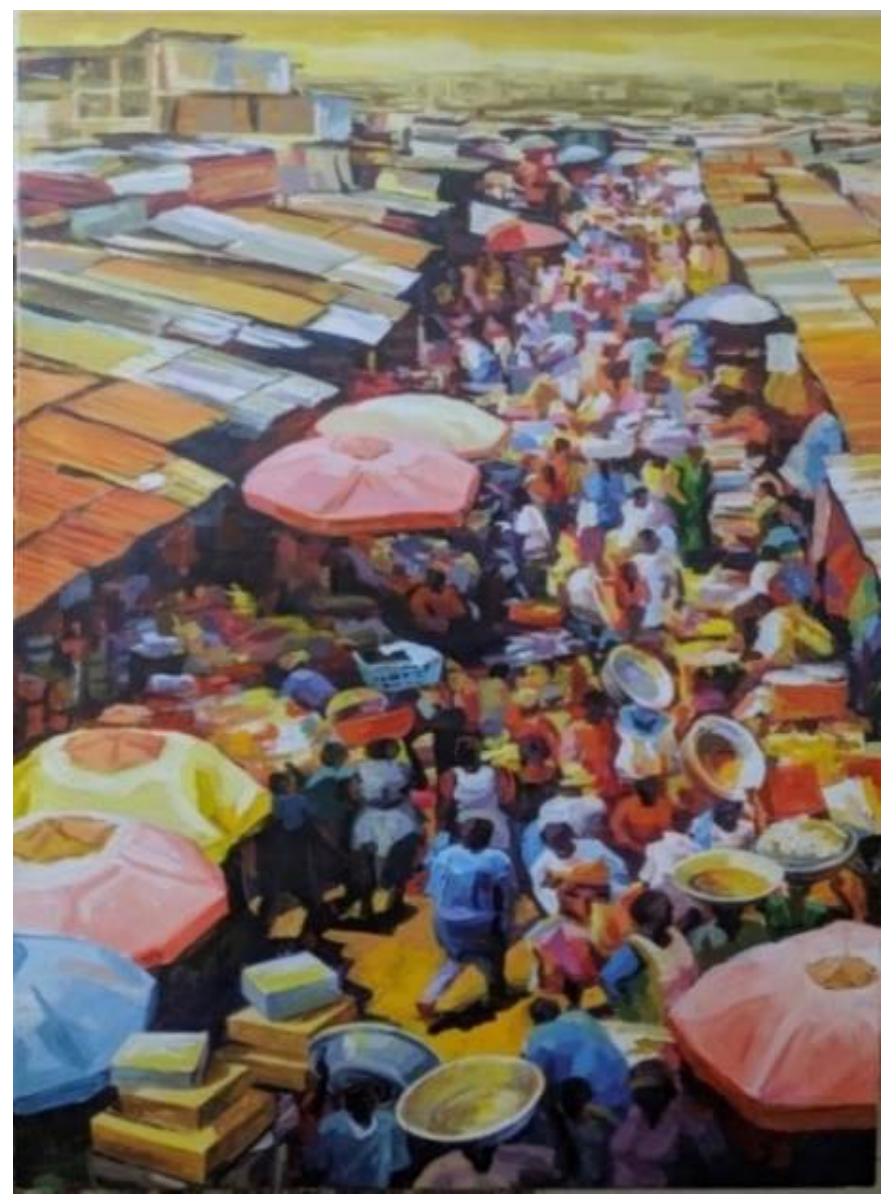

Figure 2. Afternoon Scene: Vitality

Source: Photographed by the researchers

\subsection{Evening - Preparation}

The depiction of semi-intense colours and shadows indicates that it is sunset. This period of the day is symbolic to adult or old stage of life, when energy and vitality are less intense. As could be seen from Figure 3., the hues of the colours are so dimmed to emit enough energy. At this period of day, the sun is preparing to 'go to bed' as is locally known, and to 'rise from bed' the following day. Therefore, it gathers its rays which produce 'incentives' to the colours for the production of bright hues. The withdrawal of the rays therefore darkens the colours thus subduing the brightness of the hues. Colour is not the only victim of the sun's preparation to leave. The departure of the sun enables his 'protagonist' Night to send out his 'dispatch rider' - Darkness, to stealthily crawl to gradually engulf the market at almost imperceptible pace. This sends signal of approaching Night. Users of the market (sellers and buyers alike), as a result of the herald of Night, prepare to leave for their various homes. Items are being packed and frantic preparations are made for the closing of the day.

The absence of light that weakens the brightness of colour at this period of the day is symbolic of the last stage in life of man. There is going to be a period when man will find it difficult to even move about, let alone earn a living. At that stage the strength of the individual wanes as there is little or no energy with which to work. Enough preparation ought to be made towards economising whatever is left of any amassed wealth and to plan a peaceful exit from this world. At that stage the individual attempts to, possibly, mend any 'tattered relationship.' Any acquired human relations skills are best applied at this stage to earn enough good name that will live on after the departure of the mortal remains. Documents of one's estates are gathered whilst wills bequeathing any legacy are made if they had not been done yet. The already willed documents are at this period reviewed to forestall any litigation after his/her death. 


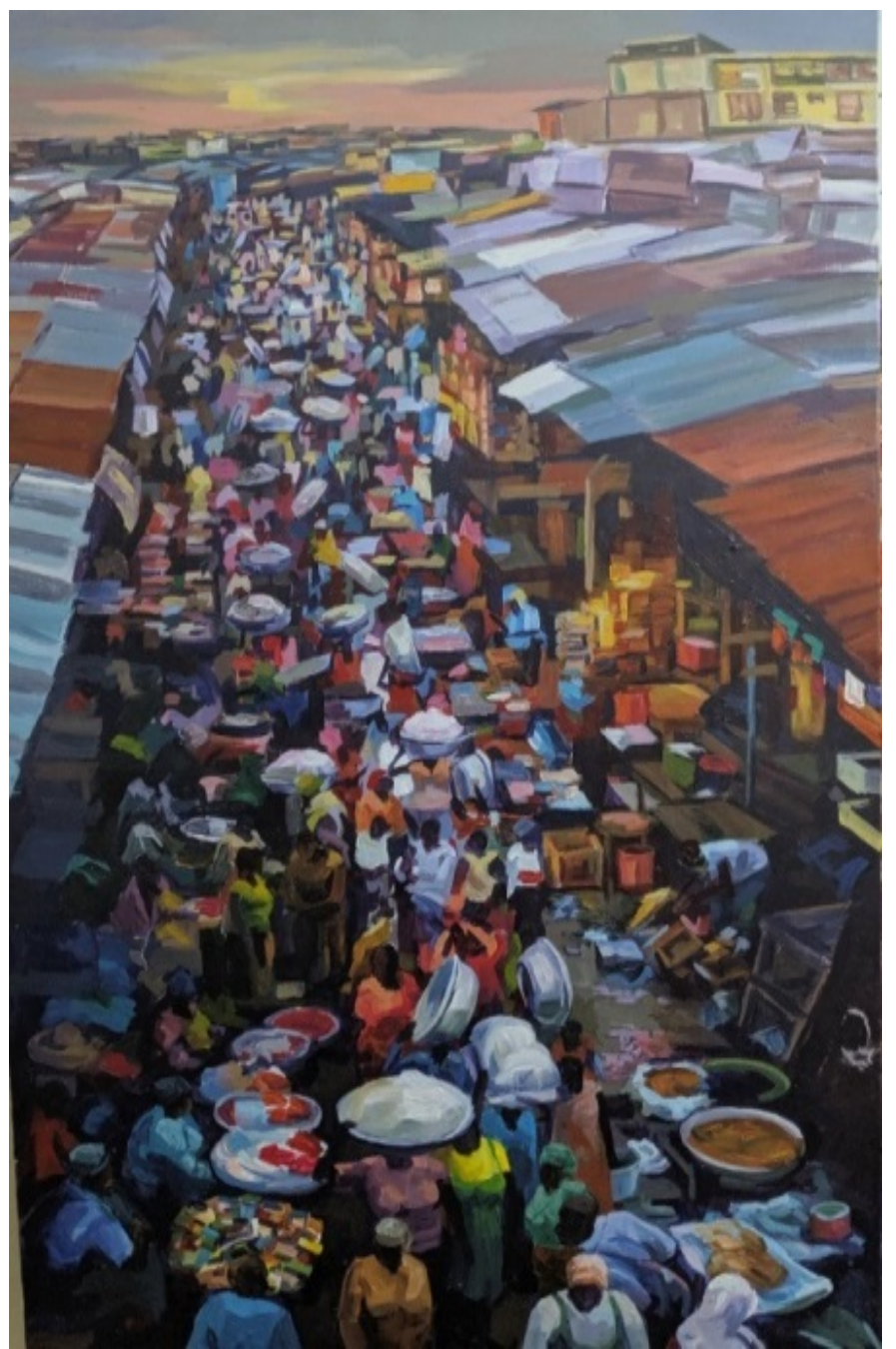

Figure 3. Evening Scene: Preparation Source: Photographed by the researchers

\subsection{Night: Death/Eventuality}

The objects in Figure 4 are represented in silhouettes. No colour, apart from black, is presented. Thus, the colours of the objects of the picture are obscured by darkness. What actually caused the colours to be obscured by darkness? Why is light retreated? As indicated in the third picture (Figure 3), 'Mr. Sun' was preparing to go to bed. Now he has actually left the market for bed thus allowing his heir, 'Mr. Darkness,' to take over the legacy bequeathed him by the sun. "Agya bi wu a Agya be tease"-When one's father dies, another father inherits his father and acts as his father. But the question is, whether the 'new father' of the market could provide hues of colour as did the 'original father.' After one's death, he/she is inherited by a relative to carry out the uncompleted activities of the deceased. His/her estates are taken care of, as well as the spouse and children. This action is indicated by darkness completely taking over whatever was owned by the sun including the market "spouse" (scenes) and the children "the hues of colour." That denotes the difference in nature of each particular 'father' and the way the heir will cater for the kids of the deceased. In the picture, the outlines of objects are seen even though the hues of colour are utterly obliterated. When one dies, the name does not immediately annihilate. Because the spouse and children are alive, they are identified with the name of the deceased. Though the colours could not be perceived, the outlines still portray the forms of the objects. When one is dead and gone, because of the legacy he/she left behind, especially children, the name still continues to 'live' till a certain period of time. This is particularly one of the reasons why everyone takes every possible means to make a name or have children or at least one child before one's death. 


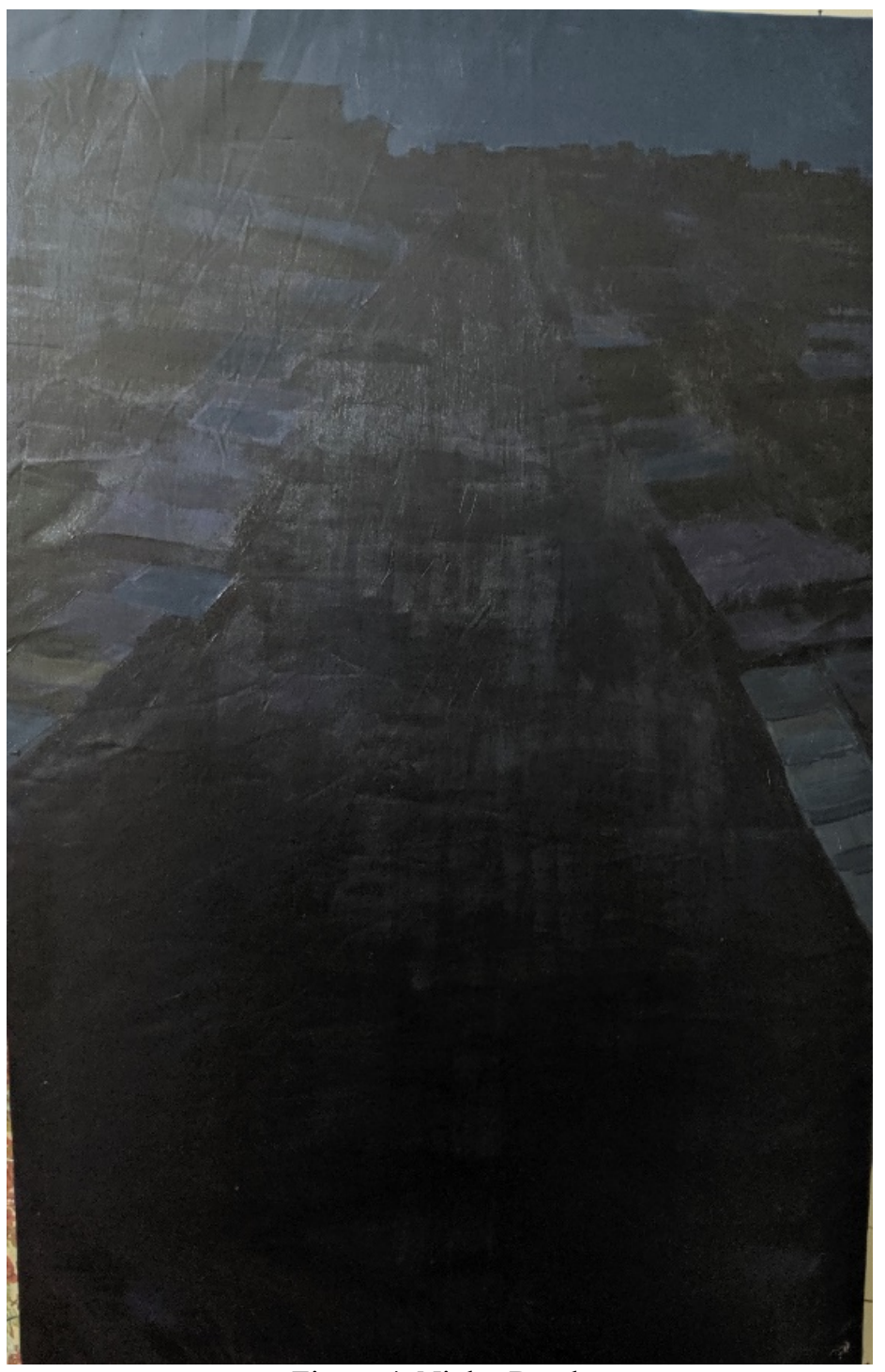

Figure 4. Night: Death

Source: Photographed by the researchers

\section{Conclusion}

From the research it could be concluded that the hues of colour demonstrated at the Kumasi Central Market exuded different levels of strength at different times of the day. Colour was observed to react differently from isolated areas to crowded areas. It was conceptually showcased with parallels in the stages in the life of man, as well as the variety of challenges one is subservient to, till one finally exists at the last stage of the rites of Passage. The colours that were observed at the market appeared from no other source than from life.

The colours that were observed at the market appeared from no other source than from the complexions of people and their clothes, the walls and roofs of the structures as well as the variety of merchandise owned by traders. The colours, besides projecting what are owned by traders, further conceptually represent the lives and actions of humans. The colours at the market, when studied in the morning, were observed to be symbolic of an infant who, by nature, is an ignoramus. The scene in the morning was foggy and therefore, quite unclear relating to uncertainty of the actions and for that matter the naivety of an infant. As the child's neurons are synonymous with 'tabular raster,' what he/she receives is what s/he, at the moment, knows and in that case, cannot forecast on any other issue. The child cannot, as a result, foresee or forestall any incidence other than what is at present before him or her. Anything 'further' cannot be seen as is portrayed with the fog in Figure 1. In the afternoon (Figure 2), the intensity, which at that period represents the youthful period in man's life, is full of vigour and vitality. The sun, which is known to be the source of energy to the colour, is at that period, exuding the most vibrant rays, thus, 'energizing' the hues. Symbolically, that period is equated with the youthful stage when man is at the peak of optimum productivity. In the evening which symbolizes the old age in man's life, the strength of the hues of colour at the market wanes towards darkness which the research characterised as the end of the life of 
man - Death.

\section{References}

Adom, D., Adu-Mensah, J. \& Kquofi, S. (2021). COVID-19 private burial with 25 persons in the lens of the mortuary rites culture in Ghana. African Identities, DOI: 10.1080/14725843.2021.1947188

Daniel Weiskopf, Department of Psychology, University of Massachusetts-Boston

Encyclopedia Britannica Online: http://www.britannica.com/EBchecked/topic/126658/colour.

Gennep, A. V. (1960). The rites of passage. University of Chicago Press.

Guerlac, H. (1986). Can There Be Colors In the Dark? USA: University of Pennsylvania Press. http://www.jstor.org/stable/2709592. Accessed on 26th October, 2010.

Mwangi, M. Saka, E.C. \& Williams G.A. (1974). Basic Science Series for Africa. Book 6. Light. Hong Kong: McGraw-Hill Far Eastern Publishers (s) Ltd.

Otto, O., Robert, E.S., Philip, R., Robert, O. B., David, L. C. (2002). Art Fundamentals. Theory and Practice School of Art. Bowling Green University. New York: McGraw- Hill Companies.

The Concise Oxford Dictionary-Tenth Edition.

TheFreeDictionary.com (C) Farlex, Inc. 2021.

Alexander, B. C. \& Norbeck, E. (2020, November 10). Rites of Passage. Encyclopaedia Britannica. https://www.britannica.com/topic/rites-of-passage 